\title{
QUERY EXPANSION RANKING PADA ANALISIS SENTIMEN MENGGUNAKAN KLASIFIKASI MULTINOMIAL NAÏVE BAYES (Studi Kasus : Ulasan Aplikasi Shopee pada Hari Belanja Online Nasional 2020)
}

\author{
Lutfiah Maharani Siniwi ${ }^{1}$, Alan Prahutama ${ }^{2}$, Arief Rachman Hakim ${ }^{3}$ \\ 1,2,3 Departemen Statistika, Fakultas Sains dan Matematika, Universitas Diponegoro \\ lutfiahmaharani27@gmail.com
}

\begin{abstract}
Shopee is one of the e-commerce sites that has many users in Indonesia. Shopee provides various attractive promos on special days such as National Online Shopping Day on December 12. Shopee site was a complete error on December 12, 2020. Complaints and opinions of Shopee users were also shared through various media, one of them was Google Play Store. Sentiment analysis was used to see the user's response to the Shopee's incident. Sentiment analysis results can be extracted to obtain information regarding positive or negative reviews from Shopee users. Sentiment analysis was performed using the Multinomial Naïve Bayes classification. the simplest method of probability classification, but it is sensitive to feature selection so that the amount of data is determined by the results of feature selection Query Expansion Ranking. The algorithm that has the highest accuracy and kappa statistic is the best algorithm in classifying Shopee's users sentiment. The results showed that the classification performance using Multinomial Naïve Bayes with $80 \%$ of the features (terms) which have the highest Query Expansion Ranking value was obtained at the accuracy and kappa statistics values are $89 \%$ and $77.62 \%$. This means that Multinomial Nave Bayes has a good performance in classifying reviews and the number of features used affects the performance results obtained.
\end{abstract}

Keywords: Shopee, National Online Shopping Day, Multinomial Naïve Bayes, Query Expansion Ranking

\section{PENDAHULUAN}

Gaya hidup dalam memenuhi kebutuhan dengan membeli secara langsung mulai ditinggalkan sebagai pencegahan untuk mengurangi persebaran Covid-19 dengan memanfaatkan jasa jual beli online melalui e-commerce. Platform e-commerce yang paling banyak digunakan oleh masyarakat Indonesia adalah marketplace. Shopee merupakan aplikasi mobile marketplace yang memiliki jumlah pengunjung tertinggi sebanyak 129 juta per bulan (iPrice, 2020). Shopee telah melakukan perubahan untuk menarik minat pelanggan agar lebih banyak bertransaksi melalui situs tersebut, seperti pemberian gratis ongkos kirim, cashback bahkan diskon besar-besaran. Pemberian berbagai promo tersebut akan lebih menarik lagi pada hari-hari spesial seperti Hari Belanja Online Nasional (Harbolnas) pada tanggal 12 Desember. Situs Shopee mengalami error secara menyeluruh pada tanggal 12 Desember 2020. Keluhan dan opini pengguna Shopee ini pun disalurkan melalui berbagai sarana salah satunya layanan Google Play Store. Analisis sentimen dilakukan untuk melihat respon pengguna mengenai aplikasi Shopee pada kejadian tersebut 
Pada penelitian ini dilakukan klasifikasi ulasan pengguna Shopee ke dalam dua sentimen, yaitu sentimen positif dan sentimen negatif. Pengklasifikasian dilakukan dengan metode Multinomial Nä̈ve Bayes. Klasifikasi Multinomial Nä̈ve Bayes merupakan pengembangan model dari algoritma bayes yang biasa digunakan dalam klasifikasi teks. Model multinomial memperhitungkan frekuensi dari setiap kata yang muncul pada dokumen di mana perhitungan hasil frekuensi ini dapat membantu klasifikasi (McCallum \& Nigam, 1998). Klasifikasi Naïve Bayes masih memiliki beberapa kekurangan yakni sangat sensitif dalam pemilihan fitur (Chen, Huang, Tian, \& Qu, 2009). Pemilihan fitur dapat membuat pengklasifikasi baik lebih efisien atau efektif dengan mengurangi jumlah data yang dianalisis, salah satunya dengan Query Expansion Ranking. Query Expansion Ranking adalah sebuah metode seleksi fitur yang berguna untuk mengurangi kompleksitas komputasi tanpa mengurangi kualitas dari analisis sentimen (Fauzi, Arifin, \& Gosaria, 2017). Hasil pengklasifikasian sentimen yang diperoleh dapat menjadi acuan dalam pengembangan e-commerce kedepannya. Berdasarkan penjelasan tersebut, tujuan yang hendak dicapai adalah mendapatkan nilai akurasi dan kappa statistic hasil kinerja klasifikasi sentimen terkait ulasan aplikasi Shopee menggunakan klasifikai Multinomial Nä̈ve Bayes dengan seleksi fitur Query Expansion Ranking. Melalui ulasan yang ditulis pengguna aplikasi Shopee diharapkan menjadi masukan guna perbaikan untuk waktu yang akan datang.

\section{TINJAUAN PUSTAKA}

\subsection{E-commerce Shopee}

Shopee Indonesia merupakan salah satu marketplace yang dimiliki oleh SEA Group yang terdapat di Singapura. Bisnis C2C (Customer to Customer) mobile marketplace yang dikelola Shopee memungkinkan untuk mampu diterima dengan mudah oleh berbagai lapisan masyarakat, termasuk di Indonesia. Sejak peluncurannya, Shopee Indonesia mengalami perkembangan yang sangat pesat, bahkan hingga tahun 2020 aplikasinya sudah di-download oleh lebih dari 129 juta pengguna (iPrice, 2020). Sasaran pengguna Shopee adalah kalangan muda yang saat ini terbiasa melakukan kegiatan dengan bantuan smartphone termasuk kegiatan berbelanja aplikasi mobile guna untuk menunjang kegiatan berbelanja yang mudah dan cepat.

\subsection{Hari Belanja Online Nasional}

Hari Belanja Online Nasional (Harbolnas) merupakan kegiatan tahunan yang diprakarasai bersama oleh enam e-commerce besar di Indonesia sejak 12 Desember 2012. Enam e-commerce tersebut yaitu Lazada Indonesia, Zalora, Blanja, PinkEmma, Berrybenka, dan Bukalapak. Harbolnas 2020 yang diawasi oleh Asosiasi E-Commerce Indonesia (idEA) berkembang signifikan terbukti dengan jumlah pesertanya yang mencapai lebih dari 250 platform belanja online (idEA, 2020).

\subsection{Text Mining}

Menurut Feldman dan Sanger (2007), text mining adalah proses mengekstrak informasi yang berguna dari sekumpulan dokumen dari waktu ke waktu melalui identifikasi pola yang menarik. Text mining adalah proses penemuan informasi baru dengan mengekstrak pola secara otomatis dari berbagai sumber teks (Kini, et al., 2015). 


\subsection{Analisis Sentimen}

Analisis sentimen adalah bidang studi yang menganalisis opini, sentimen, evaluasi, penilaian, sikap, dan perasaan terhadap entitas seperti produk, layanan, organisasi, individu, masalah, peristiwa, topik, dan atributnya (Liu, 2012). Ling, et al. (2014) menyatakan bahwa tugas dasar dalam analisis sentimen adalah mengelompokkan polaritas dari teks yang ada dalam dokumen, kalimat, atau pendapat. Polaritas mempunyai arti bahwa teks yang ada dalam dokumen, kalimat, atau pendapat memiliki aspek positif atau negatif.

\subsection{Pre-Processing Data}

Pre-Processing data sangat penting dalam melakukan analisis sentimen, terutama untuk media sosial yang sebagian besar berisi kata-kata atau kalimat yang tidak formal dan tidak terstruktur serta memiliki noise yang besar (Mujilahwati, 2016). Tahapan pre-processing yang akan dilakukan adalah sebagai berikut: case folding, cleaning, dan normalisasi kata.

\subsection{Sentiment Scoring}

Sentiment scoring dilakukan dengan menggunakan kamus sentimen, boosterwords, dan negasi. Kamus sentimen berisi kumpulan kata yang telah diberi kekuatan sentimen, yaitu kekuatan negatif antara -1 hingga -5 dan kekuatan positif antara +1 hingga +5 . Boosterwords adalah kata yang dapat meningkatkan atau mengurangi intensitas sentimen kata di sebelahnya. Kata negasi merupakan kata yang terdapat dalam suatu kalimat yang dapat mengubah orientasi dari suatu opini (Wahid \& Azhari, 2016).

\subsection{Seleksi Fitur}

Seleksi fitur merupakan tahapan mengurangi jumlah fitur yang menentukan suatu nilai kelas target, fitur irelevan, berlebihan dan data yang menyebabkan salah memberi arti pada kelas target, dan berdampak langsung pada aplikasi (Maulida, Suyatno, \& Hatta, 2016). Tahapan seleksi fitur adalah stopwords removal, stemming, tokenizing, dan Query Expansion Ranking. Stopwords removal dilakukan untuk menghilangkan kata yang sering muncul tetapi tidak relevan. Tahap stemming merupakan pengubahan kata imbuhan menjadi kata dasar. Tahap tokenizing merupakan proses pembagian kalimat menjadi potongan kata-kata.

Query Expansion Ranking (QER) adalah sebuah metode seleksi fitur yang terinspirasi dari metode Query Expansion yang berguna untuk meningkatkan kualitas query yang dimasukkan oleh pengguna kemudian digabung degan cara probabilistic weighting model untuk memberi skor pada setiap fitur (Parlar \& Özel, 2016).Peritungan dari nilai QER diperoleh persamaan:

$$
\operatorname{score}_{f}=\frac{\left|p_{f}+q_{f}\right|}{\left|p_{f}-q_{f}\right|}
$$

$p_{f}$ adalah peluang term $f$ dalam dokumen kelas positif dan $q_{f}$ dan peluang term $f$ dalam dokumen kelas negatif. Nilai-nilai peluang tersebut dihitung berdasarkan perhitungan:

$$
\begin{aligned}
& p_{f}=\frac{d f_{+}^{f}+0,5}{n^{+}+1,0} \\
& q_{f}=\frac{d f_{-}^{f}+0,5}{n^{-}+0,5}
\end{aligned}
$$


$d f_{+}^{f}$ dan $d f_{-}^{f}$ adalah jumlah dokumen positif dan negatif yang mengandung term $f$, sedangkan $n^{+}$dan $n^{-}$adalah jumlah dokumen positif dan negatif.

\subsection{Pembobotan Kata}

Pembobotan kata yang digunakan ialah metode Term Frequency-Inverse Document Frequency (TF-IDF). Manning, et al. (2009) menyatakan bahwa Term Frequency merupakan banyaknya jumlah kata atau term tertentu yang ada dalam suatu dokumen. Sementara Inverse Document Frequency adalah frekuensi kemunculan kata atau term pada seluruh dokumen. Persamaan untuk term frequency-inverse document frequency (TF-IDF) dapat dihitung menggunakan rumus sebagai berikut:

$$
W_{j, i}=\frac{n_{j, i}}{\sum_{c_{k}} n_{c_{k}, i}} \cdot \log _{2} \frac{D}{d_{j}}
$$

$W_{j, i}$ adalah pembobotan $T F-I D F$ untuk term ke-j pada dokumen ke- $i, n_{j, i}$ merupakan jumlah

kemunculan term ke- $j$ pada dokumen ke- $i, \sum_{c_{k}} n_{c_{k}, i}$ jumlah kemunculan seluruh term pada dokumen ke- $i$ pada kelas $k, D$ adalah banyaknya dokumen yang dibangkitkan, dan $d_{j}$ merupakan banyaknya dokumen yang mengandung term ke-j.

\subsection{Klasifikasi Multinomial Nä̈ve Bayes}

Klasifikasi Multinomial Nä̈ve Bayes merupakan pengembangan model dari algoritma bayes yang biasa digunakan dalam klasifikasi teks. Dokumen pada Multinomial Nä̈ve Bayes dianggap sebagai "bag of words" di mana urutan kejadian munculnya kata dalam dokumen diabaikan, sehingga setiap kata diproses menggunakan distribusi multinomial. Model multinomial memperhitungkan frekuensi dari setiap kata yang muncul pada dokumen di mana perhitungan hasil frekuensi ini dapat membantu klasifikasi (McCallum \& Nigam, 1998). Klasifikasi dokumen bertujuan untuk menentukan kelas terbaik untuk suatu dokumen. Kelas terbaik dalam klasifikasi Nä̈ve Bayes ditentukan dengan mencari maximum a posteriori (MAP) kelas $C_{M A P}$ melalui persamaan:

$$
C_{M A P}=\underset{c \in C}{\arg \max } \hat{P}(c) \prod_{j=1}^{n} \hat{P}\left(f_{j} \mid c_{k}\right)
$$

$\widehat{P}(c)$ dan $\widehat{P}\left(f_{j} \mid c_{k}\right)$ dihitung pada saat training. Persamaannya dapat dituliskan sebagai berikut:

$$
\begin{gathered}
\hat{P}\left(c_{k}\right)=\frac{N^{c_{k}}}{N} \\
\hat{P}\left(f_{j} \mid c_{k}\right)=\frac{w_{c_{k} f_{j}}+1}{\left(\sum_{w^{\prime} \in V} w_{c_{k} f_{j}}{ }^{\prime}\right)+B^{\prime}}
\end{gathered}
$$

$N^{c_{k}}$ adalah jumlah dokumen training dalam kelas $k, N$ adalah jumlah keseluruhan dokumen training dari seluruh kelas, B' merupakan jumlah IDF seluruh term pada vocabulary, $w_{c_{k} f_{j}}$ adalah bobot TF-IDF term $f_{j}$ pada dokumen dengan kelas $k$, dan $\sum_{w^{\prime} \in V} w_{c_{k} f_{j^{\prime}}}$ adalah jumlah bobot TF-IDF seluruh term pada kelas $k$.

\subsection{Evaluasi Performansi}

Proses evaluasi akurasi klasifikasi dilakukan dengan memperhatikan confusion matrix (Said \& Pranoto, 2015). Confusion matrix adalah suatu metode yang biasanya digunakan untuk melakukan perhitungan akurasi pada konsep data mining. Berikut merupakan tabel confusion matrix. 
Tabel 1. Confusion Matrix

\begin{tabular}{clc}
\hline \multirow{2}{*}{ Corect Classification } & \multicolumn{2}{c}{ Classified as } \\
\cline { 2 - 3 } & Predicted “+” & Predicted "_" \\
\hline Actual “+” & True Positives & False Negatives \\
Actual “_" & False Positives & True Negatives \\
\hline
\end{tabular}

Ukuran yang dapat digunakan untuk menilai atau mengevaluasi model klasifikasi yaitu akurasi dan kappa statistics. Akurasi merupakan nilai proporsi dari jumlah tiap kelas yang diklasifikasikan dengan benar terhadap total semua data (Han, Kamber, \& Pei, 2012). Sedangkan, Kappa Statistic adalah analisis statistik berdasarkan kesepakatan penafsir untuk data kualitatif (Vierra \& Garrett, 2015). Keduanya dapat dihitung dengan persamaan :

$$
\begin{gathered}
\text { Accuracy }=P_{0}=\frac{T P+T N}{T P+T N+F P+F N} \\
P_{c}=\left[\left(\frac{T P+F P}{\text { Total }}\right)\left(\frac{T P+F N}{\text { Total }}\right)\right]+\left[\left(\frac{F N+T N}{\text { Total }}\right)\left(\frac{F P+T N}{\text { Total }}\right)\right] \\
K=\frac{P_{0}-P_{c}}{\left(1-P_{c}\right)}
\end{gathered}
$$

\subsection{Text Visualisation}

Text visualisation merupakan teknik yang digunakan untuk menampilkan visualisasi data teks. Salah satu bentuk dari visualisasi teks adalah word cloud. Word cloud memberikan informasi yang relevan dengan menunjukkan istilah atau term yang penting dalam teks (Tessem, Bjørnestad, Chen, \& Nyre, 2015).

\section{METODOLOGI PENELITIAN}

\subsection{Jenis dan Sumber Data}

Data yang digunakan pada penelitian ini adalah data kualitatif berupa ulasan pada aplikasi Shopee di Google Play Store. Data yang akan diambil melalui web scraping pada penelitian ini berupa tanggal, nama, ulasan pengguna, dan rating dari aplikasi Shopee di Google Play Store pada laman https://play.google.com/store/apps/details?id=com.shopee.id. Data ulasan bahasa Indonesia yang diambil adalah data ulasan aplikasi Shopee pada tanggal 9 - 15 Desember 2020 dan diperoleh sebanyak 2439 data ulasan, dari 2439 ulasan tersebut dipilih sebanyak 1000 ulasan dalam kategori bahasa Indonesia dengan perbandingan data training dan data testing sebesar $80 \%: 20 \%$.

\subsection{Langkah-Langkah Analisis Data}

Penelitian ini akan dilakukan dengan bantuan software Data Miner untuk web scraping, RStudio, dan Microsoft Excel untuk analisis data. Adapun tahapan-tahapan analisis yang digunakan dalam penelitian ini diuraikan sebagai berikut:

1. Scraping data

Tahap pertama adalah mengambil seluruh data sebesar 2439 ulasan, kemudian dipilih sebanyak 1000 ulasan dalam kategori bahasa Indonesia.

2. Pre-Processing data

Sebelum digunakan perlu melakukan kan pre-processing pada data. Pre-processing yang dilakukan antara lain adalah case folding, cleaning, dan normalisasi kata. 
3. Pelabelan data dengan sentiment scoring dan manual

Melakukan pelabelan data menjadi label positif atau negatif dengan menggunakan sentiment scoring lalu dicek secara manual.

4. Stopwords removal

Data yang telah melalui tahap pelabelan selanjutnya dihilangkan kata-kata yang tidak memiliki makna sesuai dengan stoplist atau daftar kata yang dapat dihilangkan.

5. Stemming dan tokenizing

Tahap selanjutnya adalah stemming dan tokenizing. Kata-kata yag menyusun dokumen tesebut dipisahkan sehingga dapat dilakukan stemming, yakni proses pemotongan imbuhan atau pengembalian kata berimbuhan menjadi kata dasar.

6. Pembobotan kata

Metode yang digunakan pada pembobotan kata adalah pembobotan denganTF-IDF. Hasil pembobotan akan digunakan untuk proses klasifikasi.

7. Seleksi fitur Query Expansion Ranking

Proses menghilangkan fitur yang kurang relevan untuk mengurangi kompleksitas komputasi dengan Query Expansion Ranking dengan menggunakan presentase fitur sebesar $100 \%, 80 \%, 60 \%$, 40\%, dan $20 \%$.

8. Membangun model klasifikasi dan pengujian dengan Multinomial Nä̈ve Bayes

Setelah melakukan seleksi fitur, akan dilakukan klasifikasi pada dokumen yang diperlukan dengan metode Multinomial Nä̈ve Bayes.

9. Evaluasi performansi

Evaluasi performansi menggunakan confusion matrix.

10. Text visualisation

Teknik yang digunakan dalam tahap ini adalah word cloud dengan memanfaatkan frekuensi kata pada seluruh dokumen.

\section{HASIL DAN PEMBAHASAN}

\subsection{Pengumpulan Data}

Pengumpulan data pada aplikasi Shopee di Google Play Store menggunakan metode scraping data dengan menggunakan aplikasi Data Miner dengan total ulasan yang berhasil dikumpulkan adalah sebanyak 2439. Data yang diambil berupa tanggal, nama, ulasan pengguna, dan rating dari aplikasi Shopee. Ulasan yang akan diolah adalah 1000 ulasan pada Hari Belanja Online Nasional (9 - 15 Desember 2020) dengan kategori bahasa Indonesia.

\subsection{Pre-Processing Data}

Proses ini dilakukan untuk mengatasi kecenderungan data yang tidak terstruktur. Berikut merupakan tahapan pre-processing ulasan:

1. Case folding: Merubah keseluruhan teks menjadi huruf kecil agar seragam.

2. Cleaning: Menghapus karakter-karakter yang tidak dibutuhkan seperti huruf atau karakter di luar dari alfabet a-z, angka, tanda baca, dan emoticon.

3. Normalisasi kata: Mentransformasi kata-kata yang tidak sesuai Kamus Besar Bahasa Indonesia (KBBI) dan memperbaiki penulisan suatu kata. 


\subsection{Pelabelan Data}

Berdasarkan pelabelan yang telah dilakukan berdasarkan skor sentimen menggunakan kamus sentimen, boosterwords, dan negasi diperoleh 558 ulasan berlabel positif dan 442 ulasan berlabel negatif. Namun, terdapat 44 ulasan yang salah dalam pelabelan dari 1000 data ulasan. Hal tersebut mengartikan bahwa sebesar 4,4\% ulasan salah dalam pelabelan data menggunakan ketiga kamus sentiment scoring. Setelah dilakukan perbaikan pada ulasan yang salah dalam pelabelan, jumlah ulasan positif menjadi sebanyak 514 dan ulasan negatif sebanyak 486 . Hal ini disebabkan oleh hasil skor akhir yang dihitung oleh program berbeda dengan perhitungan manual.

\subsection{Stopwords Removal}

Tahap stopwords removal menggunakan kamus stoplist yang memuat 771 kata. Setelah melalui stopwords removal, jumlah kata pada seluruh dokumen adalah sebanyak 1455 fitur (term) yang sebelumnya berjumlah sebanyak 1759.

\subsection{Stemming dan Tokenizing}

Tahap stemming menggunakan package katadasaR pada Rstudio untuk mengubah kata imbuhan menjadi kata dasar. Tahap tokenizing memisahkan dokumen menjadi potongan kata dengan acuan pemisah berupa spasi.

\subsection{Pembobotan Kata}

Pembobotan kata menggunakan perhitungan Term Frequency-Inverse Document Frequency (TF-IDF). Berikut hasil nilai pembobotan kata menggunakan TF-IDF yang dapat dilihat pada Tabel 2.

Tabel 2. Pembobotan Kata dengan TF-IDF

\begin{tabular}{cccccccc}
\hline Ulasan ke- & adakan & andal & gratis & kirim & ongkos & $\cdots$ & untung \\
\hline $\mathbf{2 8 6}$ & 0 & 0 & 1,09521 & 0,81288 & 1,74145 & $\cdots$ & 0 \\
$\mathbf{6 2 9}$ & 0 & 0,73808 & 0,43808 & 0,32515 & 0 & $\cdots$ & 0 \\
$\mathbf{7 7 1}$ & 0,32975 & 0 & 0 & 0,17113 & 0,73324 & $\cdots$ & 0 \\
$\mathbf{8 6 9}$ & 0 & 0 & 0,43808 & 0,32515 & 0 & $\cdots$ & 0,67959 \\
$\vdots$ & $\vdots$ & $\vdots$ & $\vdots$ & $\vdots$ & $\vdots$ & $\ddots$ & $\vdots$ \\
$\mathbf{1 0 0 0}$ & 0 & 0 & 0 & 0 & 0 & $\cdots$ & 0 \\
\hline
\end{tabular}

\subsection{Klasifikasi}

\subsubsection{Data Training dan Data Testing}

Perbandingan data training dan data testing yang digunakan dalam penelitian ini adalah $80 \%: 20 \%$. Tabel 3 merupakan perbandingan proporsi data training dan data testing.

Tabel 3. Proporsi Data Training dan Data Testing

\begin{tabular}{cccc}
\hline Klasifikasi & Data Training & Data Testing & Total \\
\hline Positif & 411 & 103 & 514 \\
Negatif & 389 & 97 & 486 \\
Total & 800 & 200 & 1000 \\
\hline
\end{tabular}




\subsubsection{Query Expansion Ranking}

Proses seleksi fitur query expansion ranking (QER) ini adalah proses untuk mendapatkan nilai fitur pada data training. Hasil persamaan tersebut kemudian diurutkan dari nilai terkecil hingga terbesar. Berikut hasil perhitungan QER yang dapat dilihat pada Tabel 4.

Tabel 4. Hasil Perhitungan Nilai QER

\begin{tabular}{ccccccc}
\hline Ranking & Fitur & $\boldsymbol{d f}_{+}^{f}$ & $\boldsymbol{p}_{\boldsymbol{f}}$ & $\boldsymbol{d f}_{-}^{\boldsymbol{f}}$ & $\boldsymbol{q}_{\boldsymbol{f}}$ & score $_{\boldsymbol{f}}$ \\
\hline 1 & out & 1 & 0,003641 & 91 & 0,234917 & 1,031484 \\
2 & error & 1 & 0,003641 & 87 & 0,224647 & 1,032947 \\
3 & check & 1 & 0,003641 & 81 & 0,209243 & 1,035416 \\
4 & ganggu & 0 & 0,001214 & 25 & 0,065469 & 1,037774 \\
5 & masuk & 0 & 0,001214 & 21 & 0,055199 & 1,04496 \\
6 & robot & 0 & 0,001214 & 17 & 0,044929 & 1,055522 \\
7 & hilang & 0 & 0,001214 & 15 & 0,039795 & 1,062911 \\
7 & log & 0 & 0,001214 & 15 & 0,039795 & 1,062911 \\
$\vdots$ & $\vdots$ & $\vdots$ & $\vdots$ & $\vdots$ & $\vdots$ & $\vdots$ \\
140 & toko & 9 & 0,023058 & 8 & 0,021823 & 36,32913 \\
\hline
\end{tabular}

\subsubsection{Multinomial Nä̈ve Bayes}

Confusion matrix adalah evaluasi performansi yang digunakan untuk menunjukan parameter yang tepat untuk digunakan dalam mengukur performa. Berikut merupakan hasil dari klasifikasi Multinomial Nä̈ve Bayes dengan berbagai jumlah fitur (term) yang digunakan.

1. Penggunaan $100 \%$ Fitur

Seluruh fitur (term) yang ada pada data test digunakan pada proses klasifikasi pertama. Jumlah fitur yang digunakan sebanyak 1110 fitur.

Tabel 5. Confusion Matrix dengan 100\% Fitur

\begin{tabular}{ccc}
\hline \multirow{2}{*}{ Kelas Prediksi } & \multicolumn{2}{c}{ Kelas Aktual } \\
\cline { 2 - 3 } & Negatif & Positif \\
\hline Negatif & 72 & 12 \\
Positif & 15 & 101 \\
\hline
\end{tabular}

2. Penggunaan $80 \%$ Fitur

Proses klasifikasi kedua dilakukan dengan $80 \%$ fitur (term) yang memiliki peringkat tertinggi pada hasil pengolah nilai QER data training. Jumlah fitur yang digunakan sebanyak 946 fitur.

Tabel 6. Confusion Matrix dengan $80 \%$ Fitur

\begin{tabular}{ccc}
\hline \multirow{2}{*}{ Kelas Prediksi } & \multicolumn{2}{c}{ Kelas Aktual } \\
\cline { 2 - 3 } & Negatif & Positif \\
\hline Negatif & 76 & 11 \\
Positif & 11 & 102 \\
\hline
\end{tabular}


3. Penggunaan $60 \%$ Fitur

Pada proses klasifikasi berikutnya, terdapat 60\% fitur (term) peringkat QER tertinggi pada data training digunakan sebanyak 845 fitur.

Tabel 7. Confusion Matrix dengan $60 \%$ Fitur

\begin{tabular}{ccc}
\hline \multirow{2}{*}{ Kelas Prediksi } & \multicolumn{2}{c}{ Kelas Aktual } \\
\cline { 2 - 3 } & Negatif & Positif \\
\hline Negatif & 69 & 11 \\
Positif & 18 & 101 \\
\hline
\end{tabular}

4. Penggunaan $40 \%$ Fitur

Terdapat $40 \%$ fitur (term) dengan nilai QER tertinggi data training digunakan pada proses klasifikasi keempat. Jumlah fitur yang digunakan sebanyak 232 fitur.

Tabel 8. Confusion Matrix dengan 40\% Fitur

\begin{tabular}{ccc}
\hline \multirow{2}{*}{ Kelas Prediksi } & \multicolumn{2}{c}{ Kelas Aktual } \\
\cline { 2 - 3 } & Negatif & Positif \\
\hline Negatif & 66 & 11 \\
Positif & 21 & 102 \\
\hline
\end{tabular}

5. Penggunaan $20 \%$ Fitur

Sejumlah 20\% fitur (term) yang memiliki nilai QER tertinggi pada data training digunakan pada proses klasifikasi terakhir. Jumlah fitur yang digunakan sebanyak 51 fitur.

Tabel 9. Confusion Matrix dengan 20\% Fitur

\begin{tabular}{ccc}
\hline \multirow{2}{*}{ Kelas Prediksi } & \multicolumn{2}{c}{ Kelas Aktual } \\
\cline { 2 - 3 } & Negatif & Positif \\
\hline Negatif & 57 & 9 \\
Positif & 30 & 104 \\
\hline
\end{tabular}

\subsubsection{Perbandingan Hasil Kinerja Klasifikasi}

Hasil kinerja klasifikasi Multinomial Naïve Bayes berupa nilai akurasi dan kappa statistic dengan berbagai jumlah fitur yang digunakan dapat dilihat dalam Tabel 10.

Tabel 10. Perbandingan Hasil Kinerja Klasifikasi

\begin{tabular}{ccc}
\hline Jumlah Fitur & Akurasi & Kappa Statistic \\
\hline $\mathbf{1 0 0 \%}$ & $86,5 \%$ & $72,43 \%$ \\
$\mathbf{8 0 \%}$ & $89 \%$ & $77,62 \%$ \\
$\mathbf{6 0 \%}$ & $85 \%$ & $69,24 \%$ \\
$\mathbf{4 0 \%}$ & $84 \%$ & $67,01 \%$ \\
$\mathbf{2 0 \%}$ & $80,5 \%$ & $59,2 \%$ \\
\hline
\end{tabular}

\subsection{Text Visualisation}

Word cloud pada Gambar 1 memperlihatkan bahwa kata yang sering digunakan dalam komentar diantaranya adalah "shopee", "aplikasi", "belanja". Hal ini menunjukkan bahwa ulasan pengguna sesuai dengan topik aplikasi Shopee pada Harbolnas. Word cloud juga memperlihatkan kata "promo", "sale", "bagus", "mudah" yang menunjukkan tanggapan positif pengguna mengenai berbagai promo yang diberikan oleh Shopee pada Harbolnas. Selain itu, terdapat pula kata "error" dan "lambat" yang menunjukkan bahwa beberapa pengguna juga mengeluhkan server Shopee yang sempat mengalami gangguan pada hari perayaan tersebut. 


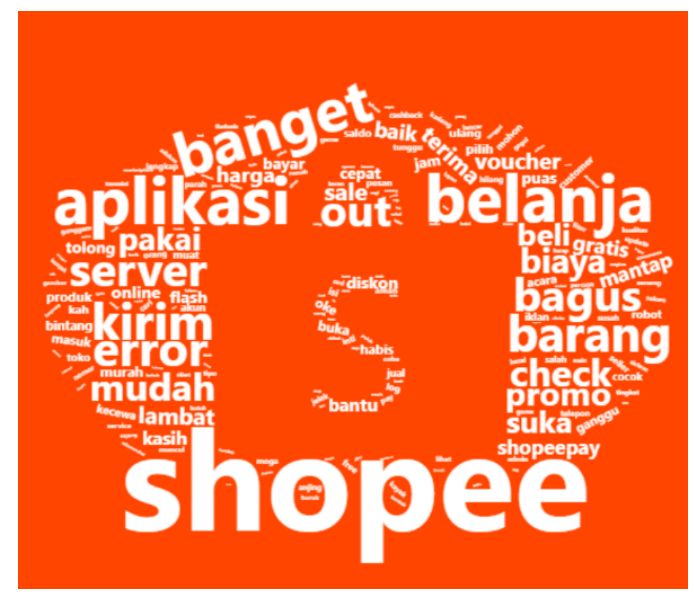

Gambar 1. Word Cloud Ulasan Aplikasi Shopee

\section{KESIMPULAN}

Opini pengguna aplikasi Shopee di Google Play Store pada Hari Belanja Online Nasional tanggal 9 hingga 15 Desember 2020 cenderung bersentimen positif. Hasil kinerja klasifikasi menggunakan Multinomial Naïve Bayes dengan $80 \%$ fitur (term) yang memiliki nilai Query Expansion Rangking tertinggi memperoleh akurasi dan kappa statistic sebesar $89 \%$ dan 77,62\%. Hal tersebut megartikan bahwa Multinomial Nä̈ve Bayes memiliki performansi yang baik dalam mengklasifikasikan ulasan dan jumlah fitur yang digunakan mempengaruhi hasil kinerja yang diperoleh.

\section{DAFTAR PUSTAKA}

Chen, J., Huang, H., Tian, S. \& Qu, Y. 2009. Feature Selection for Text Classification with Naïve Bayes. Expert Systems with Applications Vol. 36, No. 3, Hal: 5432-5435.

Fauzi, M.A., Arifin, A.Z. \& Gosaria, S.C. 2017. Indonesian News Classification Using Naïve Bayes and Two-Phase Feature Selection Model. Indonesian Journal of Electrical Engineering and Computer Science Vol. 8, No. 3, Hal: 610-615.

Feldman, R. \& Sanger, J. 2007. The Text Mining Handbook: Advanced Approaches in Analyzing Unstructured Data. Cambridge: Cambridge University Press.

Han, J., Kamber, M. \& Pei, J. 2012. Data Mining: Concepts and Techniques (3rd ed.). San Francisco: Morgan Kaufmann.

idEA. (2020). Hari Belanja Online Nasional. Tesedia: https://harbolnas.idea.or.id/ (diakses pada tanggal 1 April 2021).

iPrice. (2020). Peta E-Commerce Indonesia. Tersedia: https://iprice.co.id/insights/mapofeco mmerce/ (diakses pada tanggal 5 April 2021).

Ling, J., Kencana, I.N. \& Oko, T.B. 2014. Analisis Sentimen Menggunakan Metode Naïve Bayes Classifier Dengan Seleksi Fitur Chi Square. E-Jurnal Matematika Vol. 3, No. 3, Hal: 92-99.

Liu, B. 2012. Sentiment Analysis and Opinion Mining. Chicago: Morgan \& Claypool Publisher.

Manning, C.D., Raghavan, P. \& Schutze, H. 2009. Introduction to Information Retrieval. Cambridge: Cambridge University Press.

Maulida, I., Suyatno, A., \& Hatta, H.R. 2016. Seleksi Fitur Pada Dokumen Abstrak Teks Bahasa Indonesia. Jurnal SIFO Mikroskil Vol. 17, No. 2, Hal: 249-258. 
McCallum, A. \& Nigam, K. 1998. A Comparison of Event Models for Naïve Bayes Text Classification. 752. Workshop on Learning for Text Categorization AAAI: 1998.

Mujilahwati, S. 2016. Pre-Processing Text Mining pada Data Twitter. Seminar Nasional Teknologi Informasi dan Komunikasi 2016 (SENTIKA 2016): 18-19 Maret 2016.

Parlar, T. \& Özel, S.A. 2016. A New Feature Selection Method for Sentiment Analysis of Turkish Reviews. International Symposium on INnovations in Intelligent SysTems and Applications (INISTA): Agustus 2016.

Said, B. \& Pranoto, Y.M. 2015. Klasifikasi Data SMS Center Bupati Pamekasan Menggunakan Naïve Bayes Dengan Mad Smoothing. IdeaTech, STTS Surabaya, Hal: 92-99.

Tessem, B., Bjørnestad, S., Chen, W. \& Nyre, L. 2015. Word Cloud Visualisation of Locative Information. Journal of Location Based Services Vol. 9, No. 4.

Vierra \& Garrett. 2015. Understanding Interobserver Agreement:The Kappa Statistic. Family Medicinne, Vol. 37, No. 5, Hal: 360-363.

Wahid, D. H. \& Azhari, S.N. 2016. Peringkasan Sentimen Esktraktif di Twitter Menggunakan Hybrid TF-IDF dan Cosine Similarity. Indonesian Journal of Computing and Cybernetics Systems, Vol. 10, No. 2, Hal: 207-218. 